\title{
VIROSIS EN TOMATE TRANSMITIDAS POR SEMILLA Y SU CONTROL
}

\author{
A. Alfaro-Fernández, M. I. Font* \\ Grupo de Virología. Instituto Agroforestal Mediterráneo (IAM). Universitat \\ Politècnica de València. Camino de Vera s/n. 46022 Valencia

\section{*mafonsa@upvnet.upv.es}

\section{Resumen}

Las virosis transmitidas por semilla en el cultivo del tomate crean gran preocupación entre los productores, y son de especial atención en aquellos que se dedican al cultivo de variedades locales donde las semillas se extraen durante la campaña y son empleadas para cultivos posteriores con lo que la infección y dispersión de estos virus es mucho más frecuente. Entre los virus transmitidos por semilla en tomate destacan el virus del mosaico del tomate (ToMV) y el virus del mosaico del pepino dulce (PepMV). Ambos virus se caracterizan por transmitirse, además de por semilla, de manera mecánica fácilmente y son muy estables manteniéndose en los restos del cultivo anterior y en las infraestructuras empleadas durante el manejo del cultivo. Sin embargo, la localización de estos virus en las semillas contaminadas difiere, mientras que PepMV se localiza únicamente de manera superficial, ToMV puede encontrarse además en zonas más internas como en el endospermo. Esto hace que los tratamientos empleados para la desinfección de semillas infectadas con cada uno de estos virus sea distinto: mientras que PepMV puede ser inactivado con tratamientos químicos superficiales, el tratamiento para descontaminar semillas con ToMV debe ser térmico a elevadas temperaturas.

Palabras clave: virus, ToMV, PepMV, transmisión vertical, tratamientos

\begin{abstract}
:
Viral diseases transmitted through seed create a great concern among the tomato producers, especially those who use local varieties that harvest their own seeds from the previous growing season fruits. In this case the infection and spread of seed-transmitted viruses is more usual. ToMV and
\end{abstract}


PepMV are the two main seed-transmitted viruses which affect tomato crops. Both viruses are easily mechanically and seed transmitted, and remain infective in the plant debris of the previous crop and in the crop structures. However, the location of the virus in the contaminated seed is different. PepMV is present only externally in the seed coat, but ToMV could be also found in the endosperm. Therefore seed treatments to inactivate these two viruses are different; while PepMV could be inactivated by external chemical treatments, ToMV infected seeds should be thermal treated in order to eliminate further seedling infections.

Keywords: virus, ToMV, PepMV, vertical transmission, treatments.

\section{1.- INTRODUCCIÓN}

Las semillas son uno de los principales vehículos de transporte de organismos fitopatógenos como algunos hongos, bacterias y virus, que causan pérdidas económicas en diversos cultivos. Las enfermedades de etiología viral son más habituales en los sistemas agrícolas intensivos y tradicionales, y en el caso del tomate (Solanum lycopersicum L.) son difíciles de controlar, llegando a ser uno de los factores limitantes en la producción intensiva de tomate protegido (Jones et al., 1991). Algunos de los virus que afectan a este cultivo tienen transmisión vertical, es decir, se transmiten a la siguiente generación, mediante semillas. La transmisión de virus por semilla es importante no solo por el daño directo o indirecto que este tipo de transmisión genera produciendo la aparición aleatoria de plantas infectadas en campo que facilita una dispersión secundaria mediante vector o por contacto, dependiendo del virus; sino también por la supervivencia del virus en la semilla entre campañas y la posible diseminación del mismo a larga distancia por el comercio internacional de semilla infectada (Subramaya Sastri, 2013).

Dos de las virosis que pueden causar importantes pérdidas económicas en el cultivo del tomate valenciano son el virus del mosaico del pepino dulce (Pepino mosaic virus, PepMV) y el virus del mosaico del tomate (Tomato mosaic virus, ToMV), ambos caracterizados no solo por su fácil transmisión vía mecánica durante las labores del cultivo y roces entre plantas, sino también por transmitirse por semilla. Este segundo modo de transmisión supone una grave amenaza para el cultivo de variedades locales, entre ellas el tomate valenciano, por tratarse de variedades sin genes de resistencia a estas virosis y por el aprovechamiento de las semillas para la 
siguiente campaña, lo que provoca un mayor riesgo de infección y dispersión.

\section{2.- EL VIRUS DEL MOSAICO DEL PEPINO DULCE (Pepino mosaic virus, PepMV)}

\section{1.- Taxonomía y distribución}

El virus del mosaico del pepino dulce (PepMV) pertenece al género Potexvirus y a la familia Alphaflexiviridae. Fue descrito por primera vez en Perú en el año 1974 en pepino dulce (Solanum muricatum Aiton). Las plantas afectadas presentaban un fuerte mosaico amarillo en los brotes nuevos así como abullonados de color verde oscuro en el envés de la hoja (Jones et al., 1980). A partir del año 1999 fue detectado en plantas de tomate en más de 50 invernaderos holandeses (Van der Vlugt et al., 2000) así como en Reino Unido, donde los síntomas eran más acentuados (Wright y Mumford, 1999). Posteriormente fue detectándose, ya sobre este cultivo, en otros países de Europa provocando elevadas pérdidas económicas, debido principalmente a la gran producción de tomate en muchos países europeos. En España se detecta en el año 2000 (Jordá et al., 2001a). Hasta el momento el virus se ha detectado en distintos continentes: Europa, América (Canadá, Estados Unidos, México, Perú, Chile, y Ecuador), África (Marruecos y Sudáfrica) y Asia (Siria y China).

\section{2.- Sintomatología}

Las plantas de tomate infectadas por PepMV producen una sintomatología muy variada (van der Vlugt et al., 2000; Wright y Muford, 1999; Jordá et al., 2000a). Los síntomas más característicos de la enfermedad son mosaicos en las hojas que presentan coloraciones desde verde-claro hasta verde-oscuro (Figura 1a), en ocasiones suelen ir acompañados de abullonados (Figura 1b). Algunas plantas manifiestan un mosaico dorado más o menos distribuido por toda la parte aérea (Figura 1c). En ocasiones, las hojas únicamente presentan manchas amarillas aisladas en mayor o menor número (Figura 1d). Las hojas pueden aparecer deformadas, recortándose el limbo foliar en sus bordes que le da un aspecto rizado al foliolo (Figura 1b). Este recorte confiere en algunos casos un aspecto apuntado a los foliolos, llegando a filiformismos muy acusados, que pueden confundirse con daños por exceso de hormonas o por infección con CMV. Asimismo se han descrito, síntomas de acorchado en los márgenes de los foliolos, causados realmente por una deficiente traslocación del calcio y un 
descenso rápido de la humedad de los invernaderos, pero cuyo efecto se ve agravado por la infección viral, la cual provoca una mala adaptación de las plantas infectadas a estas situaciones de estrés (Spence et al., 2006). Ocasionalmente, los sépalos y los tallos presentan estrías cloróticas longitudinales, observándose también en algunos casos necrosis en los sépalos. Sin embargo, el síntoma más preocupante se da en frutos afectados, en los que aparecen mosaicos o jaspeados en fruto maduro (Figura 1e) debido a una mala distribución del licopeno, o incluso presentan maduración irregular (Figura 1f). Estudios realizados en Reino Unido determinaron que, aunque el nivel de producción no se ve significativamente alterado por la infección de las plantas con PepMV, existía un efecto negativo del virus sobre la calidad comercial de los frutos, que se reduce significativamente (Spence et al., 2006).

A lo largo de los años, dentro de esta gran variabilidad sintomatológica, han ido apareciendo diversas manifestaciones de la infección viral, algunas de ellas más persistentes y severas. Por ejemplo, se han descrito aislados del virus que producen diversos grados de necrosis en hojas (Verhoeven et al., 2003; Hasiów-Jaroszewska et al., 2009b), e incluso en frutos (Figura 1.8c; Córdoba-Sellés et al., 2007a).

En general, la sintomatología del virus depende tanto de las condiciones ambientales, fundamentalmente luz y temperatura, como de la variedad de tomate infectado. Se ha observado que la agresividad del virus disminuye al elevarse la temperatura e incrementarse el nivel de luminosidad (Jordá et al., 2000a; Fletcher, 2000; Lacasa et al., 2000; Lacasa y Jordá, 2002). Aparentemente, el momento de infección es otro factor influyente en la incidencia del daño que produce el virus. Los síntomas en hojas disminuyen a medida que la planta se va desarrollando; de este modo, plantas adultas muestran con frecuencia síntomas muy suaves que pueden pasar desapercibidos (Spence et al., 2006). No obstante, no cabe duda que el factor más determinante en el desarrollo de los síntomas en plantas infectadas es el propio aislado viral (Hanssen et al., 2009b). 

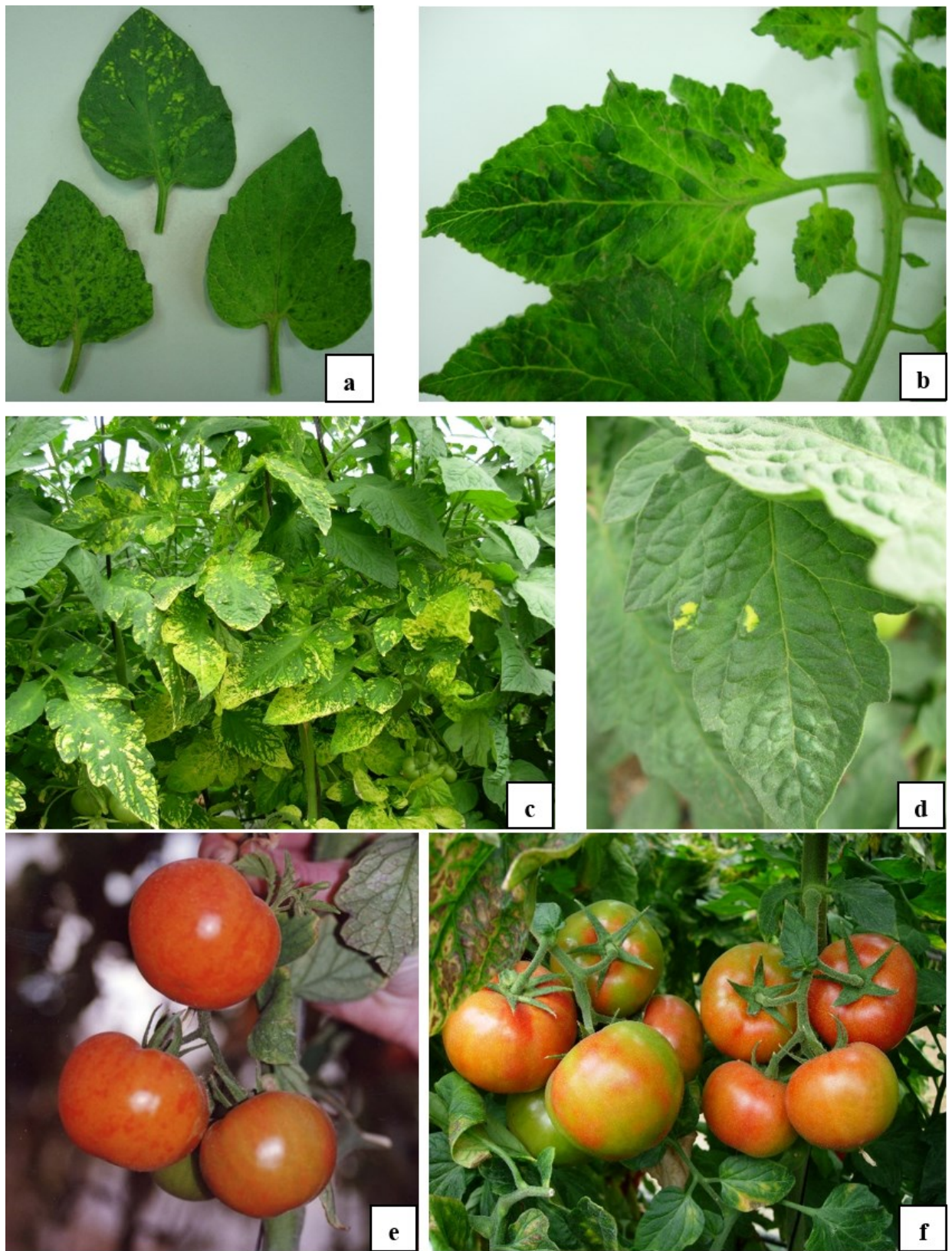

Figura 1. Síntomas de PepMV en plantas de tomate: (1a) Foliolos con coloraciones desde verde-claro hasta verde-oscuro; (1b) en ocasiones suelen ir acompañados de zonas abullonadas, recortado de los bordes del limbo foliar que le da un aspecto rizado al foliolo; (1c) mosaico dorado más o menos distribuido por toda la parte aérea; (1d) manchas amarillas aisladas en mayor o menor número; (1e) frutos maduros con mosaicos o jaspeados; (1f) o incluso presentan maduración irregular 


\section{3.- Variabilidad molecular}

PepMV se caracteriza por tener un alto nivel de diversidad genética (Hasiów-Jaroszewska et al., 2009). El primer aislado descrito se obtuvo de pepino dulce en Perú y hoy en día está considerado como aislado tipo de la cepa Peruana (PE) del virus.

Cuando apareció en Europa sobre el cultivo de tomate, todos los aislados que se detectaron eran molecularmente muy similares entre sí, con un $99 \%$ de identidad nucleotídica y comportándose biológicamente de manera muy parecida. Sin embargo, las diferencias en ambos aspectos con el aislado peruano eran significativas. A nivel biológico, el aislado PE se mostraba asintomático en las infecciones en tomate, mientras que los encontrados en Europa se comportaban de forma diferente, manifestando en ocasiones síntomas muy fuertes. Debido a estas diferencias se consideraron como dos cepas distintas del mismo virus, refiriéndose a esta última con la nomenclatura aislado tipo "europeo" (EU) (Mumford y Metcalfe, 2001; Van der Vlugt et al., 2002; Verhoeven et al., 2003; López et al., 2005).

La gran variabilidad de este virus queda patente en 2007, momento en que se caracterizan completamente dos nuevas variantes denominadas Chileno 1 (CH1) y Chileno 2 (CH2) detectadas en semilla de tomate procedente de Chile (Ling, 2007). Recientemente se ha descrito una nueva cepa del virus en poblaciones de tomate silvestre de Perú denominada PES (Moreno-Pérez et al., 2014). Por tanto, en la actualidad se considera que existen cinco cepas del virus: PE, EU, CH1, CH2 y PES.

La detección del PepMV en España ha sido gradual, poco a poco ha ido extendiéndose por casi todas las zonas productoras de tomate. Aunque todas las cepas, excepto la recientemente descrita PES, han sido detectadas en nuestro país, ya sea en infección simple o mixta, actualmente la mayoría de las infecciones que se detectan son por infecciones mixtas "EU+CH2" y simples de aislado tipo CH2 (Gómez et al., 2009). Estas dos cepas son las que muestran una mayor virulencia y adaptación al cultivo de tomate lo que explica su rápida distribución por el país (Alfaro-Fernández et al., 2013).

\section{4.- Formas de transmisión y rango de hospedantes}

Este virus posee varios mecanismos de transmisión. La principal forma de transmisión y dispersión natural del PepMV en campo es la transmisión mecánica. Gracias a su gran estabilidad, puede multiplicarse en grandes cantidades en las células de las plantas hospedadoras, siendo capaz 
de pasar de una planta a otra con el roce entre ellas o por la ropa del propio operario (Wright y Mumford, 1999). Sin embargo, la tasa de transmisión del virus es más relevante cuando el operario realiza las labores de entutorado y desbrozado (Lacasa et al., 2001), permitiendo una rápida dispersión del virus por una manipulación poco precisa.

La transmisión por insectos vectores de este virus no está aún muy esclarecida, ya que aunque sí se ha observado que abejorros del género Bombus han sido capaces de infectar distintas plantas en el momento de la polinización cuando van de flor en flor, la infección podría deberse al polen infectado llevado de una planta a otra o por una transmisión mecánica, ya que los abejorros se posan sobre hojas y flores (Lacasa et al., 2003; Shipp et al., 2008). Se ha indicado también la posible transmisión del virus mediante la mosca blanca Trialeurodes vaporariorum (Gen.) (Noël et al., 2014).

También es transmitido por semilla con un porcentaje de transmisión de hasta un 1,84\% (Córdoba-Sellés et al., 2007), lo que provoca una infección temprana en la planta y la aparición de plántulas infectadas distribuidas al azar en la parcela constituyendo reservorios del virus y focos de dispersión secundaria de la enfermedad de forma mecánica.

La propagación vegetativa es otra de las formas de transmisión que tiene ya que existe un empleo generalizado de plántula injertada sobre patrones resistentes a patógenos del suelo y que supone un alto riesgo de transmisión de virosis, especialmente para el PepMV que posee una tasa de transmisión mecánica tan elevada.

Por último, se ha detectado que el virus es capaz de transmitirse a plantas de tomate sanas mediante el agua de drenaje procedente de plantas infectadas y siempre en presencia del hongo vector Olpidium virulentus (Sahtiyanci) Karling con tasas de transmisión de hasta el 8\% (AlfaroFernández et al., 2009a). El virus no se ha detectado en aguas de los sistemas hidropónicos ni en soluciones nutritivas, sin embargo si se distribuye por ellas (Fakhro et al., 2005), probablemente debido al arrastre de trozos de tejido infectado (Stijger, 2007).

PepMV infecta fundamentalmente de manera natural a diferentes especies de solanáceas además de al tomate (S. lycopersicum): Lycopersicon chmielewskii C.M. Rick, Solanum muricatum, S. chilense (Dunal) Reiche, $S$. peruvianum L., S. pimpinellifolium L. y S. lycopersicum (Jones et al., 1980; Van der Vlugt et al., 2000; Soler et al., 2002; Moreno-Pérez et al., 2014), pero también se ha detectado en númerosas especies de la flora arvense 
(Jordá et al., 2001b; Soler et al., 2002; Córdoba et al., 2004; Soler et al., 2005; Davino et al., 2009).

\section{3.- VIRUS DEL MOSAICO DEL TOMATE (Tomato mosaic virus, TOMV)}

\section{1.- Taxonomía y distribución geográfica}

El virus del mosaico del tomate (Tomato mosaic virus, ToMV) pertenece al género Tobamovirus y a la familia Virgaviridae. Se encuentra distribuido por todo el mundo y causa daños en cultivos de tomate, tanto protegidos como al aire libre.

ToMV fue considerado durante mucho tiempo como una cepa del virus del mosaico del tabaco (TMV), pero en 1976 debido a las diferencias entre el rango de hospedantes, afinidades serológicas y secuencia del genoma viral, se determinó que se trataba de un virus diferente con entidad propia y se le denominó como se le conoce hasta hoy en día (Hollings y Huttinga, 1976).

Este virus, al igual que el TMV, constituye uno de los virus más estables e infectivos que se conocen. Como anécdota, se sabe que el virus fue hallado en un antiguo glaciar situado en Groenlandia datado entre $140 \mathrm{y}$ 500 años de antigüedad (Castello et al., 1999).

\section{2.- Sintomatología en tomate}

Los síntomas causados por la infección de ToMV en tomate varían en intensidad y aspecto dependiendo de la variedad, cepa del virus, momento de la infección y condiciones ambientales (Fletcher y MacNeill, 1971). Las plántulas de tomate afectadas pueden presentar en invierno enanismo y distorsión en la hoja, sin presentar el típico mosaico. En cambio, en verano, con temperaturas superiores a $20^{\circ} \mathrm{C}$, el enanismo y la distorsión son menos severos mientras que el mosaico es más pronunciado con la misma cepa del virus.

El síntoma típico de ToMV en tomate es un mosaico verde claroverde oscuro en las hojas (Figura 2a), casi blanco-verde o amarillo-verde en el caso de la cepa Aucuba. También puede presentar un moteado amarillo brillante, reducción de la lámina foliar y malformación de la hoja, llegando a lo que se conoce como "hoja de helecho" ("Fern leaf"). La planta afectada ve disminuido su desarrollo quedándose achaparrada y amarillenta con estrías en el tallo, curvando las hojas y llegando a la necrosis en las apicales si se trata de la cepa del virus $2^{2}$ (Alfaro-Fernández et al., 2013). 
En fruto, presenta mosaico en diferentes matices de rojo, anaranjado o amarillo además de deformaciones (Figura 2b). Los frutos afectados manifiestan maduración irregular y zonas acorchadas en la pulpa, así como reducción del tamaño y número de frutos formados.

Una manifestación sintomatológica característica es lo que se conoce con el término "goma" del tomate, en la que se necrosan los tejidos subepidérmicos. La aparición de este síntoma depende de las cepas del virus y está muy condicionada a determinadas variedades y condiciones de cultivo, principalmente desequilibrios nutricionales y falta de luminosidad (Cirulli y Ciccarese, 1975).

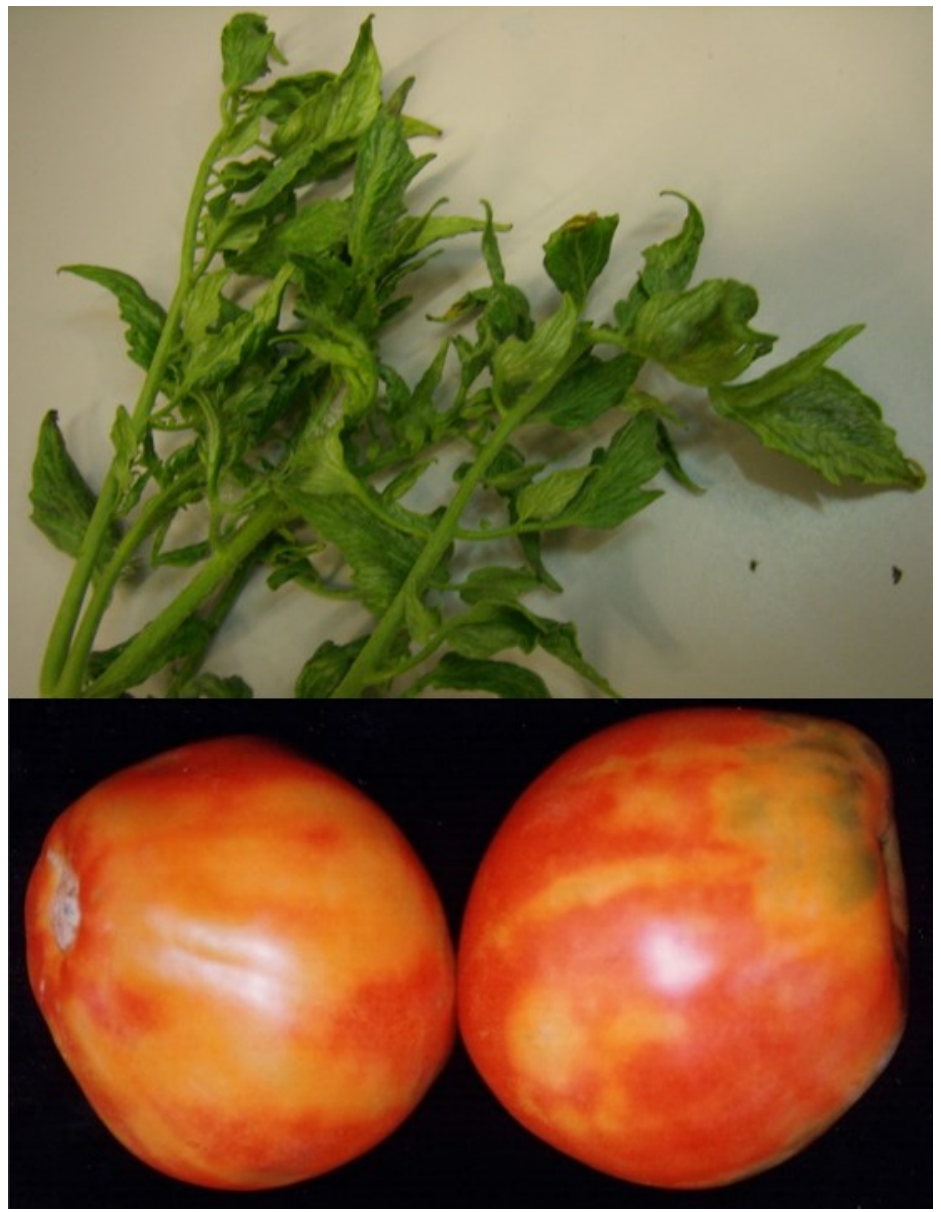

Figura 2. Síntomas de ToMV en tomae: (a) Mosaico verde claro-verde oscuro en hojas de tomate; (b) Mosaico en fruto. 


\section{3.- Forma de transmisión y rango de hospedantes}

ToMV se transmite con gran facilidad de forma mecánica, por contacto entre plantas o por los trabajadores que rozan con su ropa plantas infectadas y plantas sanas al realizar las diferentes labores de cultivo. Además es un virus capaz de transmitirse por semilla alcanzando porcentajes de transmisión muy altos, habiéndose descrito hasta un 16,9\% (Subramanya Sastry, 2013). Este porcentaje varía en función de la concentración del virus en la semilla, que fundamentalmente depende a su vez del momento en el que se infectó la planta (Chitra et al., 1999). El virus se localiza en la cubierta de la semilla y en el endospermo siendo al germinar la semilla cuando se produce la infección de la plántula (Broadbent, 1965).

La transmisión del virus por agentes vectores no ha sido probada, aunque sí se sabe que algunos insectos comedores de hojas, como los escarabajos, pueden rozar con sus mandíbulas el tejido vegetal produciéndose la inoculación del virus, pero se trataría igualmente de una transmisión mecánica (Kiyotsugu et al., 2000).

El virus es capaz de sobrevivir en el suelo durante largos periodos de tiempo, aún en condiciones poco propicias para la planta, por su gran estabilidad ocasionando la infección del siguiente cultivo (Lanter et al., 1982). Este virus se ha encontrado incluso en agua y nubes (Castello et al., 1999).

La lista de hospedantes es inmensamente amplia. Afecta a más de nueve familias botánicas destacando a especies pertenecientes a las familias Aizoaceae, Amaranthaceae, Chenopodiaceae, Rosaceae y Solanaceae, entre otras (MAGRAMA, 2011). Dentro de las solanáceas, por su importancia económica, se encuentra en tomate (S. lycopersicon), pimiento (Capsicum anuum L., berenjena ( $S$. melongena L.), pepino dulce $(S$. muricatum) y tabaco (Nicotiana tabacum L.) (Alfaro-Fernández et al., 2013).

\section{4.- MEDIDAS GENERALES DE CONTROL Y TRATAMIENTOS DE DESINFECCIÓN DE SEMILLA FRENTE A PepMV y ToMV}

La mayor parte de las estrategias de control frente a enfermedades de etiología viral se han dirigido hacia la prevención de la infección para impedir la entrada del patógeno, su establecimiento y dispersión. En general las medidas adoptadas son de tipo higiénico y de mejora en el manejo del 
cultivo. En el caso de PepMV y ToMV al tratarse de virus muy estables que se transmiten fácilmente de forma mecánica algunas de estas medidas son:

- El lavado de manos en una solución de agua jabonosa caliente y mojado de los zapatos en soluciones desinfectantes al entrar al invernadero por parte del operario.

- El uso de protecciones desechables en cabeza, cuerpo, manos y pies.

- Adopción de una estricta disciplina de trabajo en parcela, realizando siempre todas las operaciones de cultivo en la misma dirección, sentido y orden, siempre dejando la zona sospechosa de infección para el final de la jornada.

- Eliminación de los posibles reservorios naturales del virus como frutos caídos al suelo, restos de cultivos anteriores y plantas arvenses.

- Tratamientos desinfectantes a soluciones hidropónicas y sobre substratos, aunque es preferible el empleo de nuevos sustratos en cada campaña.

- La biosolarización o cierre del invernadero durante un cierto tiempo en verano con objeto de subir la temperatura, podría ser otra manera de eliminar las partículas del virus.

- En ambas virosis se ha desarrollado la práctica de la preinmunización o protección cruzada que consiste en la inoculación de las plántulas en el momento del trasplante con cepas no agresivas del virus para que la presencia de estas en las plantas las proteja frente a la infección posterior con cepas agresivas del virus.

- En caso de aparición de síntomas sospechosos de la enfermedad, eliminación completa de las plantas afectadas y las contiguas, sacándolas de la zona de cultivo en una bolsa de plástico para evitar posibles contactos de estas con otras plantas sanas.

- Antes de la siguiente campaña, desinfección de estructuras, en caso de cultivo protegido.

- Empleo de semilla sana.

\section{1.- Tratamientos de desinfección de semillas frente a PepMV y ToMV}

Para verificar el empleo de semilla sana en caso de tomate valenciano y evitar la infección y posterior dispersión en campo de PepMV 
y ToMV debe procederse siempre a utilizar semillas que hayan sido tratadas previamente con los tratamientos pertinentes para la inactivación de estos virus.

Para la selección de los tratamientos de desinfección de virus en semilla es importante conocer donde se localiza el virus a tratar en ésta, ya que la localización del virus en las capas superficiales de la semilla permiten su inactivación con tratamientos químicos, sin embargo la presencia de partículas virales en capas más internas de las semillas hace que estos tratamientos superficiales sean ineficaces. En este último caso hay que recurrir a tratamientos térmicos que penetren hacia capas más internas de la semilla permitiendo la inactivación del virus (Subramanya Sastry, 2013).

Mientras que PepMV se localiza en las partes superficiales de la cubierta seminal (EPPO, 2013), ToMV se localiza tanto en la cubierta como en el endospermo (Huttinga y Rast, 1995). Esta diferencia hace que los tratamientos eficaces para la inactivación de ambos virus no sean los mismos. Hasta el momento, la inactivación de ToMV de las semillas se consigue mediante tratamientos de termoterapia de $24 \mathrm{~h}$ a $80^{\circ} \mathrm{C}$, aunque algunos estudios indican que los tratamientos de desinfección químicos como fosfato trisódico y lejía han dado buenos resultados (Gooding, 1975), así como otros rangos de temperaturas y tiempos como $70^{\circ} \mathrm{C}$ durante $24 \mathrm{~h}$ (Silva et al., 2011). En el caso de semillas infectadas con PepMV se han ensayado diferentes tratamientos tanto químicos como la inmersión de las semillas en una solución con fosfato trisódico al 10\% durante 3 horas, la inmersión en una solución de pectinasa ( $3 \mathrm{~g} / \mathrm{L})$ durante 24 horas, la inmersión en una solución de pectinasa ( $3 \mathrm{~g} / \mathrm{L})$ y ácido clorhídrico al $2 \%$ durante 24 horas y la inmersión en una solución de pectinasa $(3 \mathrm{~g} / \mathrm{L})$, ácido clorhídrico al $2 \%$ y lejía comercial al $30 \%$ durante 24 horas, como de termoterapia como a $80^{\circ} \mathrm{C}$ durante 24 horas, $72^{\circ} \mathrm{C}$ durante 48 horas y $70^{\circ} \mathrm{C}$ durante 96 horas. A raíz de estos ensayos se determinó que el tratamiento con fosfato trisódico al $10 \%$ era el más recomendable por tener un mayor efecto en la limpieza y desinfección de las semillas infectadas, no afectar a la germinación y ser el más rápido de realizar frente al resto de tratamientos (Córdoba-Sellés et al., 2007). Sin embargo en trabajos posteriores se demostró que este tratamiento no era efectivo al 100\% describiéndose en este último ensayo el tratamiento con peróxido de hidrógeno al 4\% durante 30 minutos como el tratamiento más eficaz para la inactivación de PepMV (Bosch et al., 2016). El tratamiento con $\mathrm{H}_{2} \mathrm{O}_{2}$ favorece la germinación de las semillas en el caso del trigo (Ishibashi et al., 2008), por lo que en la 
actualidad se está evaluando el efecto de este tratamiento en la vida útil de las semillas para comprobar que sea apropiado para el almacenamiento de semillas tratadas durante largos periodos.

En resumen, según los ensayos realizados para la inactivación de virus en semilla de tomate valenciano realizados por el Grupo de Virología del Instituto Agroforrestal Mediterráneo de la Universidad Politécnica de Valencia, el tratamiento más efectivo para la inactivación de PepMV sería la inmersión de la semilla durante media hora en una solución de peróxido de hidrógeno al $4 \%$ y en el caso de ToMV la termoterapia a $80^{\circ} \mathrm{C}$ durante $24 \mathrm{~h}$. Por lo tanto, es importante conocer la problemática del cultivo ya que los tratamientos para la inactivación de estos virus son diferentes, aunque su sintomatología en campo pueda ser similar. En caso de sospechar la coinfección con ambos virus se debe realizar, por tanto una combinación de ambos tratamientos.

\section{5.- REFERENCIAS BIBLIOGRÁFICAS}

Alfaro-Fernández, A.; Córdoba-Sellés, M.; Herrera-Vásquez, J.; Cebrián, M.; Jordá, C. 2009a. Transmission of Pepino mosaic virus by the fungal vector Olpidium virulentus. Journal of Phytopathology 158 (4): 217226.

Alfaro-Fernández, A.; Córdoba-Sellés M.; Font, I.; Jordá, C. 2013. Virosis relevantes en el cultivo del tomate: detección, diagnóstico y control. Valencia: PHYTOMA-España.

Bosch, R.; Blanco, L.; Alfaro-Fernández, A.; Estévez-Caparrós, J.M.; Font, M.I. 2016. Evaluation of chemical seed disinfection treatments efficacy to eliminate Pepino mosaic virus (PepMV) from infected cherry tomato seeds. Proceedings de $5^{\text {th }}$ International Symposium on tomato diseases pp. 46. Málaga, Spain.

Broadbent, L. 1965. The epidemiology of tomato mosaic virus.II. Seed transmission of TMV. Annals of Applied Biology 56, 177-205.

Castello, J.; Rogers, S.; Starmer, W.; Catranis, C.; Ma, L., Bachand, D.; Smith, J. 1999. Detection of Tomato mosaic tobamovirus RNA in ancient glacial ice. Polar Biology 22(3), 207-212. 
Chitra, T.; Prakash, H.; Albrechtsen, S.; Shetty, H.; Mathur, S. 1999. Infection of tomato and bell pepper by ToMV and TMV at different growth stages and establishment of virus in seeds. Journal of Plant Pathology 81(2), 123-126.

Cirulli, M.; Ciccarese, F. 1975. Interactions between TMV isolates, temperature, allelic condition and combination of the Tm resistance genes in Tomato. Phytopathologia Mediterranea 14, 100-105.

Córdoba, M.C.; Martínez-Priego, L.; Jordá, C. 2004a. New natural hosts of Pepino mosaic virus in Spain. Plant Disease 88, 906.

Córdoba-Sellés, M.C.; García-Rández, A.; Alfaro-Fernández, A.; Jordá, C. 2007. Seed transmission of Pepino mosaic virus and efficacy of tomato seed disinfection treatments. Plant Disease 91, 1250-1254.

Davino, S.; Accotto, G.P; Masenga, V.; Torta, L.; Davino, M. 2009. Basil (Ocimum basilicum) a new host of Pepino mosaic virus. Plant Pathology 58, 407.

EPPO, 2013. PM 7/113 (1) Pepino mosaic virus. Bulletin OEPP/EPPO Bulletin (2013) 43 (1), 94-104

Fakhro, A.; Paschek, U.; von Bargen, S.; Schwarz, D.; Bütner, C. 2005. Distribution and spread of Pepino mosaic virus (PepMV) in tomatoes cultivated in a re-circulated hydroponic system. In: Introduction and spread of invasive species symposium, June, 09-11 June 2005, Berlin, Germany.

Fletcher, J.; MacNeill, B. 1971. Influence of environmental, cultivar and virus strain on the expression of Tobacco mosaic virus symptons in tomato. Journal Plant Sciences 51, 101-107.

Fletcher, J. 2000. Pepino mosaic, a new disease of tomatoes. Horticultural Development Council Fact Sheet 12, 6

Gómez, P.; Sempere, R.; Elena, S.; Aranda, M. 2009. Mixed infections of Pepino mosaic virus strains modulate the evolutionary dynamics of this emergent virus. Journal of Virology, 83(23): 12378-12387.

Gooding, G. (1975). Inactivation of Tomato mosaic virus on tomato seed with trisodium orthophosphate and sodium hypochlorite. Plant Disease Reporter 59, 770-772. 
Hanssen, I.M.; Mumford, R.; Blystad, D-R.; Cortez, I.; HasiówJaroszewska, B.; Hristova, D.; Pagán, I.; Pereira, A.M.; Petter, J.; Pospieszny, H.; Ravnikar, M.; Stijger, I.; Tomassoli, L.; Varveri, C.; van der Vlugt, R.; Nielse, S.L.; 2009a. Seed transmission of Pepino mosaic virus in tomato. European Journal of Plant Pathology 126: 145..

Hasiów-Jaroszewska, B.; Borodynko, N.; Pospieszny, H.; 2009a. Infectious RNA transcripts derived from cloned cDNA of a Pepino mosaic virus isolate. Archives of Virology 154, 853-856.

Hasiów-Jaroszewska, B.; Pospieszny, H.; Borodynko, N. 2009 b. New necrotic isolates of Pepino mosaic virus representing the $\mathrm{Ch} 2$ genotype. Journal of Phytopathology 157, 494-496.

Hollings, M.; Huttinga, H. 1976. Tomato Mosaic Virus. CMI/AAB. Description of plants viruses 156, 6 .

Huttinga, H., Rast, A. 1995. Tomato mosaic tobamovirus. Viruses of plants. CAB International, Wallingford, 1302-1310.

Ishibashi, Y.; Yamamoto, K.; Tawaratsumida, T.; Yuasa, T.; IwayaInoue M. 2008. Hydrogen peroxide scavenging regulates germination ability during wheat (Triticum aestivum L.) seed maturation. Plant Signal Behaviour 3(3), 183-188.

Jones, R.A.C.; Koening, R.; Lesemann, D. E. 1980. Pepino mosaic virus, a new Potexvirus from pepino (Solanum muricatum). Annals of Applied Biology 94, 61-68.

Jones, J.B.; Jones, J.P.; Stall, R.E.; Zitter, T.A. 1991. Diseases caused by viruses. Zitter, T.A., ed. Compendium of Tomato diseases. St. Paul, MN, USA. APS Press, 100.

Jordá, C.; Lázaro, A.; Font, I.; Lacasa, A.; Guerrero, M.; Cano, A. 2000a. Nueva enfermedad del tomate. Phytoma España 119, 23-28.

Jordá, C.; Lázaro-Pérez, A.; Martínez-Culebras, P.; Abad, P. 2001a. First report of Pepino mosaic virus on tomato in Spain. Plant Disease 85, 1292.

Jordá, C.; Lázaro-Pérez, A.; Martínez-Culebras, P.; Lacasa, A. 2001b. First report of Pepino mosaic virus on natural hosts. Plant Disease $85,1292$. 
Kiyotsugu, O.; Shinichi, K.; Mitsuo, K.; Junchi, N.; Satoshi, T.; Takeshi, O. 2000. Tobacco mosaic virus is transmissible from tomato to tomato by pollinating bumblebees. Journal of General. Plant Pathology, 66(1), 71-74.

Lacasa, A.; Jordá, C.; Guerrero, M.M.; Lázaro, A.; Cano, A.; Font, I.; Alcázar, A.; Oncina, M. 2000. La nueva enfermedad del tomate, producida por el virus del mosaico del pepino dulce (Pepino mosaic virus, PepMV). FECOAM 28, 35-40.

Lacasa, A.; Guerrero, M.M.; Hita, I.; Martínez, M.A.; Hernández, M.D.; 2001. La diseminación del virus del mosaico del pepino dulce (Pepino mosaic virus) en las labores de entutorado y desbrotado de plantas de tomate. Boletín Sanidad Vegetal Plagas 27, 489-501.

Lacasa, A.; Guerrero, M.M.; Hita, I.; Martínez, M.A.; Jordá, C.; Bielza, P.; Contreras, J.; Alcázar, A.; Cano, A. 2003. Implicaciones de los abejorros (Bombus spp.) en la dispersión del virus del mosaico del pepino dulce (Pepino mosaic virus) en cultivos de tomate. Boletín Sanidad Vegetal Plagas 29, 393-403.

Lacasa, A.; Jordá, C. 2002. El virus del mosaico del pepino dulce y sus connotaciones en el cultivo del tomate. Terralia 26, 58-65.

Lanter, J.; McGuire, J.; Goode, M. 1982. Persistence of Tomato mosaic virus in tomato debris and soil under field conditions. Plant Disease 66(7), 552-555.

Ling, K.S., 2007. Molecular characterization of two Pepino mosaic virus variants from imported tomato seed reveals high levels of sequence identity between Chilean and US isolates. Virus Genes 34, 1-8.

López, C.; Soler, S.; Nuez, F. 2005. Comparison of the complete sequences of three different isolates of Pepino mosaic virus: size variability of the TGBp3 protein between tomato and L. peruvianum isolates. Archives of Virology 150, 619-627.

Moreno-Pérez, M.; Pagán, I.; Aragón-Caballero, L.; Cáceres, F.; Fraile, A.; García-Arenal, F. 2014. Ecological and genetic determinants of Pepino mosaic virus emergence. Journal of Virology 88(6), 3359-3368. 
Mumford, R.A.; Metcalfe, E.J. 2001. The partial sequencing of the genomic RNA of a UK isolate of Pepino mosaic virus and the comparison of the coat protein sequence with others isolates from Europe and Peru. Archives of Virology 146, 2455-2460.

Noël, P.; Hance, T.; Bragard, C. 2014. Transmission of the Pepino mosaic virus by whitefly. European Journal of Plant Pathology 138, 23-27.

Shipp, J.L.; Buitenhuis, R.; Stobbs, L.; Wang, K.; Kim, W.S.; Ferguson, G. 2008. Vectoring Pepino mosaic virus by bumble-bees in tomato greenhouses. Annals of Applied Biology 153, 149-155.

Silva, P.P.; Freitas, R.A.; Nascimento, W.M. 2011. Detection of Tomato mosaic virus in tomato seed and treatment by thermotherapy. Acta Horticulturae 917, 303-308.

Soler, S.; López, C.; Nuez, F. 2005. Natural occurrence in viruses in Lycopersicon spp. in Ecuador. Plant Disease 89, 1244.

Soler, S.; Prohens, J.; Diez, M.J.; Nuez, E. 2002. Natural occurrence of Pepino mosaic virus in Lycopersicon species in Central and Southern Peru. Journal of Phytopathology 150, 45-53.

Spence, N.J.; Basham, J.; Mumford, R.A.; Hayman, G.; Edmondson, R.; Jones, D.R. 2006. Effect of Pepino mosaic virus on the yield and quality of glasshouse-grown tomatoes in the UK. Plant Pathology 55, 595-606.

Subramanya Sastry, K. (2013). Seed-borne plant virus diseases. Springer.

van der Vlugt, R.A.A.; Stijger, C.C.; Verhoeven, J.T.J.; Lesermann, D.E. 2000. First report of Pepino mosaic virus in tomato. Plant Disease 84, 103.

van der Vlugt, R.A.A.; Cuperus, C.; Vink, J.; Stijger, C.C.M.M.; Lesemann, D-E.; Verhoeven, J.Th.J.; Roenhorst J.W. 2002. Identification and characterisation of Pepino mosaic potex virus in tomato. Bulletin OEPP/EPPO Bulletin 32, 503-508.

Verhoeven, J.T.J;, van der Vlugt, R.A.A.; Roenhorst, J.W. 2003. High similarity between tomato isolates of Pepino mosaic virus suggest a common origin. European Journal of Plant Pathology 109, 419-425. 
Wright, D.; Mumford, R. 1999. Pepino mosaic potexvirus (PepMV). First records in tomato in United Kingdom. Central Science Laboratory, York, UK. Plant Disease Notice, 89. 